\title{
26415 - INHALED PROSTACYCLIN TO TREAT PULMONARY HYPERTENSION POST CV SURGERY
}

\section{Michelle Way Registered Respiratory Therapist, Tim Aye, $\operatorname{FRCP}(C)$; St. Mary's General Hospital, Kitchener, ONTARIO, Canada}

\section{INTRODUCTION:}

Inhaled prostacylin (iPGI2) is a selective pulmonary vasodilator to treat pulmonary hypertension. The purpose of this study was to evaluate the initial hemodynamic effects of inhaled prostacyclin (Flolan; GlaxoSmithKline) post cardiac surgery, and to assess the cost of therapy.

\section{METHODS:}

Patients with pulmonary hypertension (defined as mean PAP $>30 \mathrm{mmHg}$ or systolic PAP $>45 \mathrm{mmHg}$ ) or right ventricular failure, in the perioperative period, were started on the Flolan protocol in the CVOR or the CVICU. Clinicians first attempted to improve right ventricular function by optimizing hemodynamic and ventilatory parameters before initiating Flolan protocol.

Flolan was reconstituted in $50 \mathrm{ml}$ of sterile glycine diluent to achieve a final concentration of $30 \mathrm{mcg} / \mathrm{ml}$ and attached to the inspiratory limb of the ventilator circuit using a low-flow nebulizer system (MiniHEART nebulizer). Initial therapy was started at $180 \mathrm{mcg} / \mathrm{hr}$, as per protocol. Dose remained at this level for the first 4 hours and decreased to $148,120,90,60$, and $30 \mathrm{mcg} / \mathrm{hr}$ at 4, 6, 8, 10, and $12 \mathrm{hrs}$ respectively. Hemodynamic measurements were performed within the first hour of treatment. Flolan was weaned provided no negative response was observed. Data from the first hour of treatment was gathered retrospectively. Paired student $t$-tests were used to evaluate the changes seen in hemodynamic parameters with $p<0.05$ considered as significant. All patients pre-operatively signed consent to use their data in the institution's database. RESULTS:

14 patients were admitted into the protocol. Patients were post cardiovascular surgery (14\% CABG, 14\% valve(s) only, 36\% CABG + valve, 7\% CABG + VSD repair, 29\% complex aortic reonstruction + valve). 3 patients were excluded due to insufficient data available for review. 3 patients died; 2 as a result of intractable bleeding secondary to coagulopathy and 1 secondary to RV failure unresponsive to treatment.

Of the 11 patients studied at $180 \mathrm{mcg} / \mathrm{hr}$, the mean dose was $41 \mathrm{ng} / \mathrm{kg} / \mathrm{min}$. 91\% (10/11) of the patients evaluated had an immediate response to the treatment (reduction of MPAP $>10 \%$ ). Of the patients studied, the mean reduction in MPAP was $28 \%$ (9mmHg). The mean MPAP:MAP was also found to be reduced by $28 \%$ indicating that systemic blood pressure had no overall effect on changes in PAP. No clinically significant changes in MAP or CI were observed. (see table) The mean duration of treatment was 27.3 hours $( \pm 8.3)$ with a mean treatment cost of $\$ 160.00$ per patient.

DISCUSSION:

This study demonstrates that inhaled prostacyclin reduces pulmonary artery pressure without a concomitant reduction in systemic artery pressure. We conclude that iPGI2 is a cost effective alternative to nitric oxide to treat pulmonary hypertension and RV failure after cardiac surgery.

REFERENCE: 
J Thorac Cardiovasc Surg, 2004;1058-1067

Table

\begin{tabular}{|c|c|c|c|}
\hline & BASELINE & POSTI-PGI & P value \\
\hline MPAP(minHg) & $33.4 \pm 6$ & $24.1 \pm 6$ & 0.001 \\
\hline MIPAPIIAP & $0.438 \pm 0.08$ & $0.347 \pm 0.06$ & 0.033 \\
\hline MAP(mmHg) & $77 \pm 7$ & $70 \pm 7$ & $0.101(\mathrm{~ns})$ \\
\hline CI & $2.89 \pm 0.98$ & $2.97 \pm 0.42$ & $0.786(\mathrm{~ns})$ \\
\hline
\end{tabular}

